\title{
Outcomes of Arthroscopic Debridement of Extensor Carpi Radialis Brevis Versus Platelet-Rich Plasma Injection in Management of Resistant Lateral Epicondylitis
}

\author{
M.M.Ibraheem, M.A.Mashhour, M.S.Singer and M.G.Montaser \\ Orthopedic Surgery Dept.,Faculty of Medicine, Benha Univ., Benha, Egypt \\ E-Mail: M.Ibraheem @gmail.com
}

\begin{abstract}
Although lateral epicondylitis has become synonymous with tennis, 95\% of cases occur in non-tennis-playing individuals. Redundant assignments and developments including the elbow and wrist place a person in danger of creating horizontal epicondylitis. The point of this investigation was to look at results of arthroscopic arrival of extensor carpi radialis brevis with PRP infusion for the board of safe horizontal epicondylitis. Strategies: The examination was led on 42 patients partitioned into 2 gatherings. The main gathering (21 patients) went through arthroscopic debridement of ECRB birthplace, and the other gathering (21 patients) had PRP infusion. All patients had at first nonoperative treatment, including calming drug, rest, action change, active recuperation, propping, and corticosteroid infusions. The usable signs were headstrong manifestations for in any event a half year or irritation of indications in spite of nonoperative treatment for a very long time. Results and end: Our examination discoveries propose the accompanying ends: PRP infusions and arthroscopic ECRB discharge are both powerful in the short and mid term follow up. PRP patients in some cases show helpless outcomes which require extra infusions or elective sort of treatment as arthroscopic discharge. The two techniques ( PRP infusion and arthroscopic discharge) were protected and very much acknowledged by the patients. Longer term follow up might be required for patients to identify any protests repeat particularly in manual and substantial laborers.
\end{abstract}

Keywords: Arthroscopic, Debridement, Extensor Carpi Radialis, Platelet-Rich Plasma, Epicondylitis.

\section{Introduction}

The expression "grass tennis arm" first appeared in the writing in an article by Morris, conveyed in Lancet in 1882. The following year, in 1883, Major portrayed a comparative condition in the British Medical Journal, even more accurately generating the articulation "tennis elbow". It is acknowledged that some place in the scope of $10 \%$ to half of people who reliably play tennis or other racquet sports will experience equal epicondylitis in the long run [1].

Yet sidelong epicondylitis has gotten indistinguishable from tennis, $95 \%$ of cases occur in nontennis-playing individuals. Monotonous tasks and advancements including the elbow and wrist place an individual at risk for making level epicondylitis. Delegates working in nonstrenuous occupations had a $1 \%$ event, while those working a debilitating position had a $7-11 \%$ recurrence [2].

The extensor carpi radialis brevis (ECRB) starting has been the required as the specific site of pathology. The essential sore in tennis elbow is a degenerative tendinopathy of ECRB cause. Histologically the hurt tendon shows confirmation of energetic fibroblastic and vascular entrance, or angiofibroblastic hyperplasia. Biomechanical assessment by Riek et al showed that unconventional compressions of the ECRB muscle during strike tennis swings, especially in fledgling players, cause excess microtrauma that achieve tears to the origin of the tendon and resultant sidelong epicondylitis [3].

In numerous patients, sidelong epicondylitis can be managed adequately with nonoperative measures including rest, nonsteroidal quieting drug, propping, and non-nosy treatment. If imperative, other nonsurgical medications, for instance, various mixtures can be used. Corticosteroid imbuements have been used for long time at any rate late examinations showed no drawn out profitable effect. Reports of the use of blood things, for instance, autologous blood and various centralizations of platelet-rich plasma (PRP), have been brought into the composition. PRP has gotten growing revenue across various musculoskeletal educates and has been by and large applied clinically to stimulate tissue recovering [4].

The legitimate composing fuses a wide variety of cautious choices for flat epicondylitis going from percutaneous to open to arthroscopic treatment. It is represented that after open strategies, patients generally have drawn out postoperative trouble with a conceded reappearance of work and wearing activities stood out from arthroscopic strategy. Another great situation of arthroscopy is ID and the leading body of chaperon elbow pathology [5].

In spite of the way that it is a common condition, and various nonoperative and cautious choices exist, there stays a general nonappearance of concurrence regarding ideal treatment. The inspiration driving the current examination is to consider delayed consequences of arthroscopic release versus PRP mixture in treatment of safe even epicondylitis.

The purpose of this examination was to consider aftereffects of arthroscopic appearance of extensor carpi radialis brevis with PRP implantation for the heads of safe equal epicondylitis.

\section{Patients and methods}

The study was conducted on 42 patients divided into 2 groups. The first group (21 patients) underwent arthroscopic debridement of ECRB origin, and the other group (21 patients) had PRP injection.

The patients were diagnosed with lateral epicondylitis by history and physical examination using the following criteria: 
- Tenderness at the lateral epicondyle over the common extensor origin.

- Pain during resisted dorsiflexion of the wrist with the elbow in full extension.

All patients had initially nonoperative treatment, including anti-inflammatory medication, rest, activity modification, physical therapy, bracing, and corticosteroid injections. The operative indications were refractory symptoms for at least 6 months or aggravation of symptoms despite nonoperative treatment for 3 months.

\section{Exclusion criteria}

- Previous surgery or fracture of the affected elbow.

- Cervical radiculopathy.

- Entrapement neuropathy in upper limb like carpal or cupital tunnel syndromes.

Preoperatively, the demographic and other characteristics of the patients, including age, sex, hand dominance, affected side, symptom duration and aggravation, smoking, underlying disease (diabetes mellitus or hypertension), and number of previous steroid injections, were recorded.

The level of sports activity was defined as high (dynamic or contact sports, such as boxing, basketball, rugby, and tennis), medium (static sports, such as golf, yoga, and running), low (milder sports activities), and none ( no sports activities). A high manual work as lifting, knocking, and digging was defined as heavy work, and a low manual work with less physical activity, was defined as non heavy work.

Radiologic investigations; All patients had undergone $\mathrm{x}$-ray radiography for detection of previous surgery or fracture of the affected elbow.

Clinical results: All patients were examined and evaluated preoperatively and at 6, and 12 months postoperatively. Patients were assessed and asked to

Table (1) Socio-demographic criteria among the studied groups. assess their elbow function and pain using different scores including:

- Visual Analog Scale (VAS) for pain (range, 0 [no pain] to 100 [agonizing pain]).

- The Disability of the Arm, Shoulder, and Hand (DASH) score.

- Patient-rated tennis elbow evaluation (PRTEE) score.

- Patient satisfaction score consisting of 10 points score where 10 is fully satisfied and 1 is not satisfied at all.

\subsection{Statistical analysis}

The data were coded, entered and processed on computer using SPSS (version 24). The results were represented in tabular and diagrammatic forms then interpreted. Mean, standard deviation, range, frequency, and percentage were use as descriptive statistics. The following tests were done: Chi-Square test $\mathrm{X}^{2}$ was used to test the association variables for categorical data. Student's t-test was used to assess the statistical significance of the difference between two population means in a study involving independent samples, with normal distribution.

\section{Results}

The age of the patients in group (A) ranged from 29 52 years with a mean of $(39.43 \pm 6.31)$ years, and in group (B) ranged from 28 - 54 years with a mean of (38.86 \pm 6.61$)$ years with $P$ value equal (0.78) which mean that no significant differences between the two groups regarding age. Sex: In group (A) thirteen patients $(61.9 \%)$ were males and eight patients $(38.1 \%)$ were females while in group (B), fifteen patients $(71.4 \%)$ were males and six (28.6\%) patients were females with $\mathrm{P}$ value equal (0.51) which mean that no significant differences between the two groups regarding sex, Table (1).

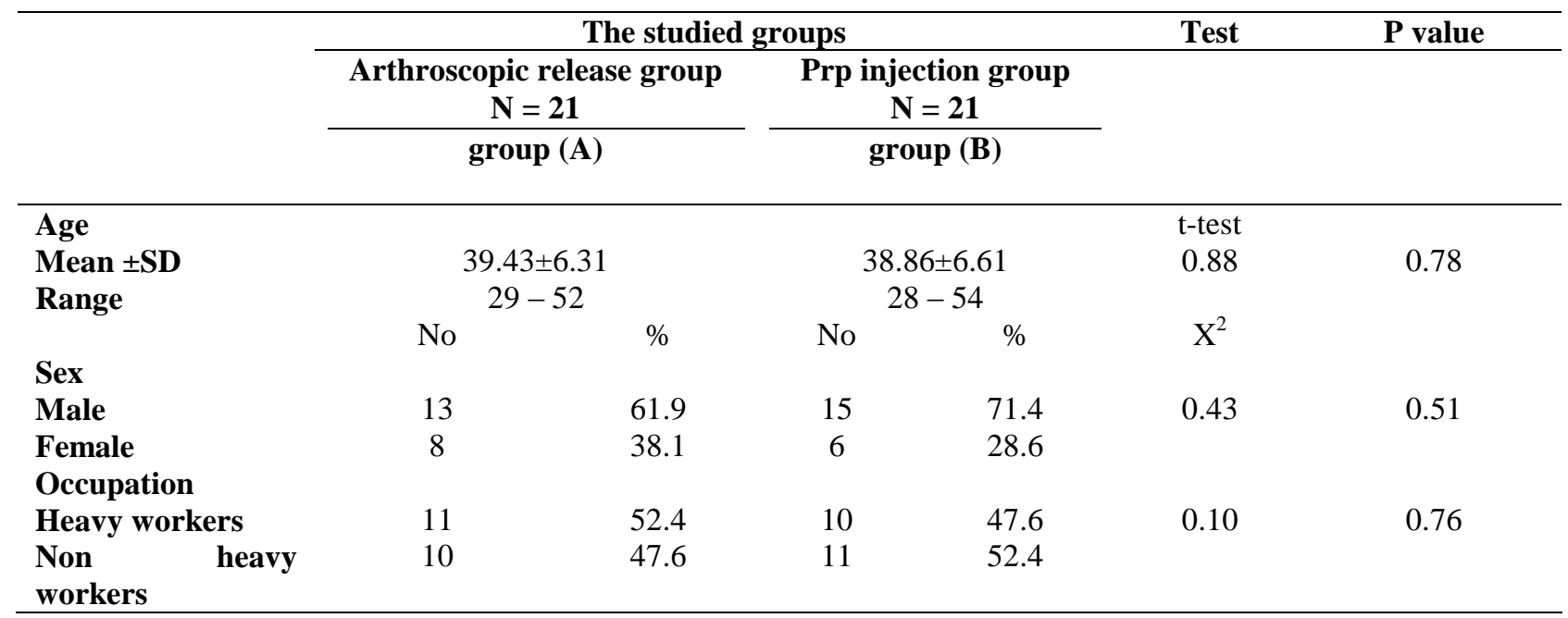

$\mathrm{SD}=$ Standard deviation, $\mathrm{X}^{2}=$ Chi square test. 
Pre and postoperative scores of patients in arthroscopic release group (group A) : Table (2).

Table (2) Pre and postoperative scores of patients (group A) .

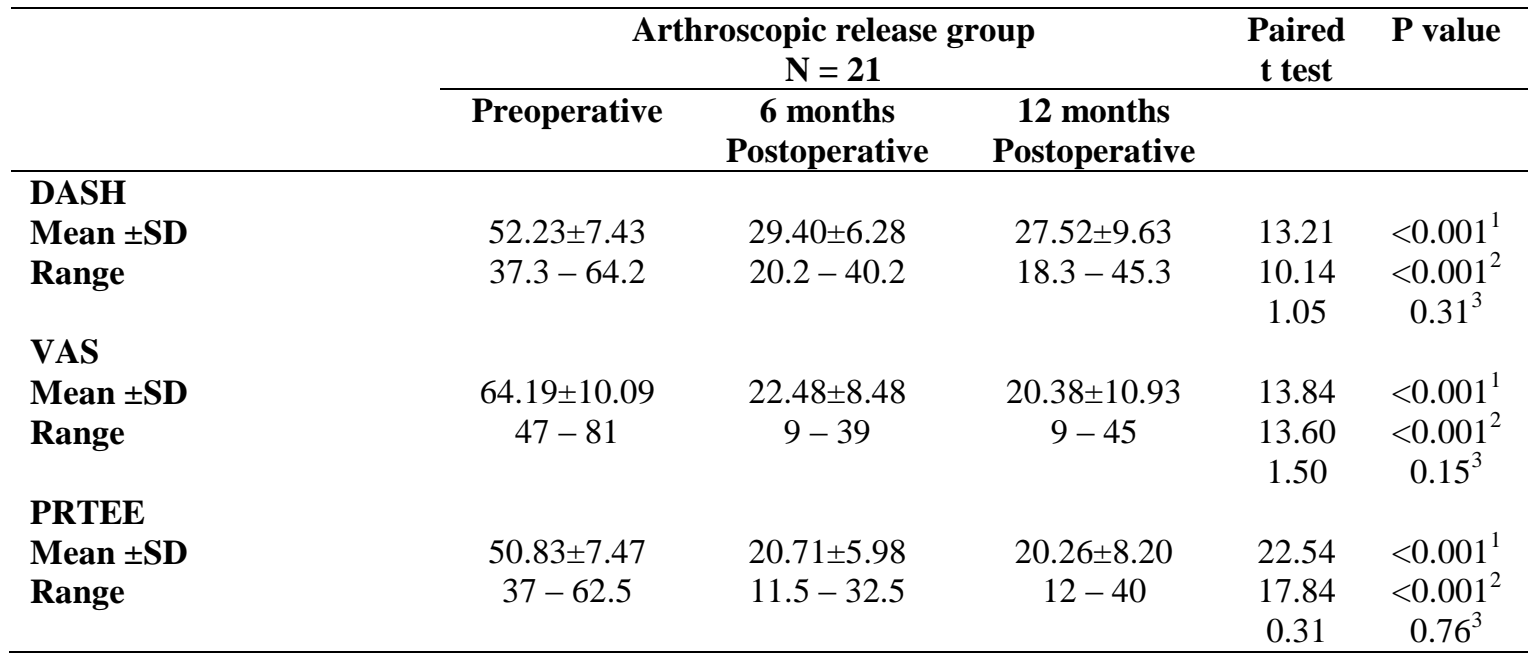

$$
\begin{gathered}
1=\text { comparing preoperative and } 6 \text { months postoperative } \\
2=\text { comparing preoperative and } 12 \text { months postoperative } \\
3=\text { comparing } 6 \text { months postoperative and } 12 \text { months postoperative }
\end{gathered}
$$

\begin{tabular}{|c|c|c|c|c|c|}
\hline & & $\begin{array}{c}\text { Prp injection grou } \\
\mathrm{N}=21 \\
\end{array}$ & & $\begin{array}{c}\text { Paired } \\
\text { t test }\end{array}$ & P value \\
\hline & Preoperative & $\begin{array}{l}6 \quad \text { months } \\
\text { Postoperative }\end{array}$ & $\begin{array}{l}12 \text { months } \\
\text { Postoperative }\end{array}$ & & \\
\hline $\begin{array}{l}\text { DASH } \\
\text { Mean } \pm \text { SD } \\
\text { Range }\end{array}$ & $\begin{array}{l}52.17 \pm 7.58 \\
36-65\end{array}$ & $\begin{array}{l}31.85 \pm 5.98 \\
23.7-45.7\end{array}$ & $\begin{array}{l}29.19 \pm 8.77 \\
19.3-45.7\end{array}$ & $\begin{array}{l}12.32 \\
10.18 \\
1.71\end{array}$ & $\begin{array}{l}<0.001^{1} \\
<0.001^{2} \\
0.10^{3}\end{array}$ \\
\hline $\begin{array}{l}\text { VAS } \\
\text { Mean } \pm \text { SD } \\
\text { Range }\end{array}$ & $\begin{array}{l}64.24 \pm 11.09 \\
47-81\end{array}$ & $\begin{array}{l}24.81 \pm 7.21 \\
12-37\end{array}$ & $\begin{array}{l}22.71 \pm 8.81 \\
12-40\end{array}$ & $\begin{array}{l}12.91 \\
13.05 \\
1.74\end{array}$ & $\begin{array}{l}<0.001^{1} \\
<0.001^{2} \\
0.09^{3}\end{array}$ \\
\hline $\begin{array}{l}\text { PRTEE } \\
\text { Mean } \pm \text { SD } \\
\text { Range }\end{array}$ & $\begin{array}{l}51.21 \pm 7.32 \\
40-63\end{array}$ & $\begin{array}{l}22.33 \pm 6.85 \\
13-39.5\end{array}$ & $\begin{array}{l}18.60 \pm 8.66 \\
10-39.5\end{array}$ & $\begin{array}{l}12.58 \\
13.58 \\
1.90\end{array}$ & $\begin{array}{l}<0.001^{1} \\
<0.001^{2} \\
0.07^{3}\end{array}$ \\
\hline
\end{tabular}

Pre and post injection scores of patients in Prp injection group (group B) : Table (3).

Table (3) Pre and post injection scores of patients (group B).

\begin{tabular}{|c|c|c|c|c|}
\hline \multirow[b]{2}{*}{6 months Postoperative score } & \multicolumn{2}{|c|}{ The studied groups } & \multirow[t]{2}{*}{ t-test } & \multirow{2}{*}{ P value } \\
\hline & $\begin{array}{c}\text { Arthroscopic release group } \\
\qquad \mathbf{N}=\mathbf{2 1} \\
\operatorname{group}(\mathrm{A})\end{array}$ & $\begin{array}{c}\text { Prp injection group } \\
\mathbf{N}=\mathbf{2 1} \\
\text { group (B) }\end{array}$ & & \\
\hline DASH & & & & \\
\hline Mean \pm SD & $29.40 \pm 6.28$ & $31.85 \pm 5.98$ & 1.30 & 0.20 \\
\hline Range & $20.2-40.2$ & $23.7-45.7$ & & \\
\hline
\end{tabular}

Post operative scores in both groups in table (4).

Table (4) Postoperative scores of patients in both studied groups. 
Table (4) Continue

\begin{tabular}{|c|c|c|c|c|}
\hline \multicolumn{5}{|l|}{ VAS } \\
\hline Mean \pm SD & $22.48 \pm 8.48$ & $24.81 \pm 7.21$ & 0.94 & 0.34 \\
\hline Range & $9-39$ & $12-37$ & & \\
\hline \multicolumn{5}{|l|}{ PRTEE } \\
\hline Mean \pm SD & $20.71 \pm 5.98$ & $22.33 \pm 6.85$ & 0.82 & 0.42 \\
\hline Range & $11.5-32.5$ & $13-39.5$ & & \\
\hline \multicolumn{5}{|c|}{12 months Postoperative score } \\
\hline \multicolumn{5}{|l|}{ DASH } \\
\hline Mean \pm SD & $27.52 \pm 9.63$ & $29.19 \pm 8.77$ & 0.59 & 0.56 \\
\hline Range & $18.3-45.3$ & $19.3-45.7$ & & \\
\hline \multicolumn{5}{|l|}{ VAS } \\
\hline Mean \pm SD & $20.38 \pm 10.93$ & $22.71 \pm 8.81$ & 0.76 & 0.45 \\
\hline Range & $9-45$ & $12-40$ & & \\
\hline \multicolumn{5}{|l|}{ PRTEE } \\
\hline Mean \pm SD & $20.26 \pm 8.20$ & $18.60 \pm 8.66$ & 0.64 & 0.53 \\
\hline Range & $12-40$ & $10-39.5$ & & \\
\hline
\end{tabular}

In group (A), patient satisfaction ranged from $3-9$ with a mean of $(6.76 \pm 1.95)$, and in group (B) patient satisfaction ranged from $2-9$ with a mean of $(6.19 \pm 2.23)$ , with $\mathrm{P}$ value equal (0.35) which mean that no significant differences between the two groups regarding patient satisfaction. Patient satisfaction in group (A) was excellent in four patients $(19.0 \%)$, good in twelve patients $(57.1 \%)$, fair in five patients $(23.8 \%)$, and no patient complaint from poor prognosis, while in group (B), patient satisfaction was excellent in three patients $(14.3 \%)$, good in eleven patients $(52.4 \%)$, fair in six patients $(28.6 \%)$, and poor in one patient $(4.8 \%)$ with $\mathrm{P}$ value equal (0.74) which mean that no significant differences between the two groups regarding patient satisfaction, Fig (1).

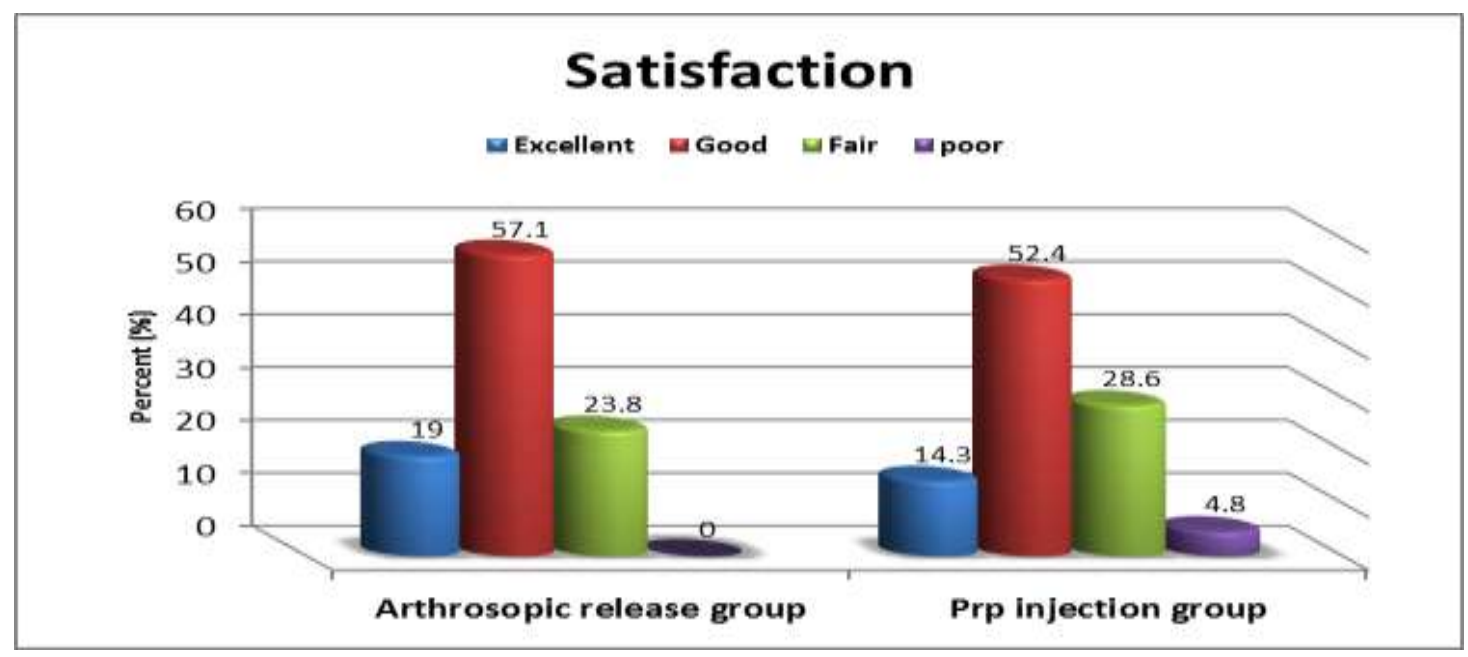

Fig (1) Patient satisfaction among the studied groups

\section{Discussion}

The head discoveries of our investigation show that PRP infusion and arthroscopic parallel delivery are both successful in easing torment and reestablishing capacity in the short and mid term follow up in patients with ongoing sidelong epicodylitis .

PRP patients revealed fundamentally improved torment scores at early development and a slight yet non critical improvement at mid term follow up ; their PRTEE score was equivalent to arthroscopic gathering of patients at a half year postoperative and a year postoperative with no huge distinction between 2 gatherings at midterm follow up and this is reliable with the investigation of Giovanni Merolla et al [6].

In the arthroscopy gathering of patients, the torment and PRTEE scores improved at record-breaking focuses. Patients with delicacy to palpation over the sidelong epicondyle and agony with opposed wrist expansion were more various in the PRP gathering, though patients treated by arthroscopy had essentially more prominent hold strength from week 10 to the furthest limit of the investigation. Torment during movement was somewhat lower in the arthroscopy gathering. These information propose that the arthroscopic approach might be helpful 
in specialists engaged with substantial manual assignments.

A precise survey of the impacts of PRP on sidelong epicondylitis clinical results, distributed in 2013, discovered 3 randomized clinical examinations revealing early positive outcomes, like our investigation; PRP altogether improved short-and mid-term VAS torment and Disability Arm, Shoulder and Hand work scores contrasted and corticosteroid, bupivacaine and autologus blood infusion [7].

Extra examinations affirm the valuable impacts of PRP in horizontal epicondylitis. As indicated by an organization meta-examination contrasting PRP, corticosteroid, and autologus blood infusion, distributed in 2015, PRP improves torment and lessens the danger of entanglements, while autologus blood improves torment, incapacity scores, and the pressing factor torment limit however includes a higher danger of difficulties. [8] Nevertheless, Krogh and associates found that despite the fact that autologus blood and PRP were altogether better than fake treatment, just 1 preliminary was at generally safe of inclination. [9]

In our examination there was 1 poor clinical results found at 1 year which demonstrated that PRP infusion didn't ease the indications in some pateients who need further treatment in mid term follow up for those patients [7]. When moderate techniques neglect to guarantee a worthy personal satisfaction, open [10] or arthroscopic delivery can be thought of. [11] Good long haul results have been accounted for [12] with open extraction of ECRB tissue influenced by tendinosis.

In our examination it was experienced no neurologic deficiencies, with no normal $\mathrm{x}$ beam imaging for the patients to recognize heterotrophic hardening with no patient grievances to speculate this intricacy likelihood . In our examination, no helpless patients results were experienced more than a year postoperative development among patients who were treated with arthroscopic discharge. Arthroscopic ECRB ligament discharge requires adequate experience and alert to maintain a strategic distance from iatrogenic nerve injury as elbow entrances are set up.

Despite the fact that the explanation behind the between-bunch contrasts found in mid-term results is hard to clarify, the current information brief a few contemplations. PRP guaranteed great torment decrease until 1 year, when torment logically deteriorated, bringing about expanded agony during movement during later development. A new meta-investigation has recognized 2 examinations where PRP was more successful than fake treatment, regarding clinical results, at 26 and 52 weeks [9]; another precise audit has announced great consequences of PRP contrasted and other infusion medicines at subsequent meet-ups of 3,6 , and a year. Albeit these information affirm the valuable clinical impacts of PRP on torment and elbow work in the short and mid term, the absence of a careful gathering for correlation and the utilization of various result measures in certain examinations forestall an immediate examination with our discoveries. On the other hand, the arthroscopy patients in our investigation experienced huge help with discomfort in the short, mid term and adequate torment during movement. It could be estimated that postoperative restoration and extending added to the better mid term clinical results of arthroscopy patients, however the accessible clinical information are inadequate to help any end. It is sensible to guess that that evacuation of the harmed container, particular debridement and resection of the ECRB cause with conservation of ECRL strands, and epicondyle decortication incited age of new tissue with more prominent protection from stress and stacking. Moreover, joint investigation permitted barring a radiocapitellar synovial plica and empowered evaluation of the seriousness of capsular harm and discovery of any ligament and bone wounds which affirmed the analysis of parallel epicondylitis and treat the going with different pathologies if present too. The better torment scores found in the arthroscopy bunch were particularly noteworthy in subjects engaged with rehashed business related strong exercises. The reason for this planned, randomized examination was to analyze the adequacy of autologous PRP infusions and arthroscopic horizontal delivery in treating persistent sidelong epicondylitis. So it was conjectured that the 2 medicines would have comparative mid term adequacy. Our outcomes loan some help to the speculation that penetration of autologous PRP and arthroscopic parallel delivery has close adequacy in ongoing sidelong epicondylitis yet arthroscopic discharge gathering of patients had marginally more fulfillment results and better capacity during movement; the great clinical torment results found in the short and mid term in the two gatherings . Our discoveries give new knowledge into a subject of incredible premium, where the viability of remedial systems is as yet discussed; these information can be utilized to talk about with patients the most proper way to deal with deal with their condition. The great shortand mid-term results given by PRP legitimize its reasonable use as a first-line helpful methodology and in quite a while who don't wish to go through a medical procedure; extra PRP infusions can be controlled in the event of diligent agony and delicacy. The arthroscopic approach is solid, negligibly intrusive, and gives midterm clinical benefit.

\section{Conclusion}

Our study discoveries recommend the accompanying ends: PRP infusions and arthroscopic ECRB discharge are both viable in the short and mid term follow up. PRP patients once in a while show helpless outcomes which require extra infusions or elective sort of treatment as arthroscopic discharge. Sterile and aseptic conditions should be ready for PRP infusion to evade disease which is a perilous difficulty . Non steroidal mitigating medications ought to be evaded after PRP infusion as it might meddle with platelet work. Arthroscopic discharge guaranteed better mid-term results regarding relief from discomfort and grasp strength recuperation particularly during movement. Particular consideration should be 
taken during entry situation for arthroscopic delivery to evade neurological injury arround the elbow. Arthroscopic discharge as a technique for therapy of ongoing horizontal epicondylitis permits the specialist to review other intraarticular pathologies if present and treat them also which is an extraordinary favorable position of arthroscopic discharge over PRP infusion strategy. Restoration is vital and an integrative piece of treatment routine for patients who go through arthroscopic discharge a medical procedure which starts promptly, with dynamic and latent scope of movement practices for the elbow. the two methodology ( PRP infusion and arthroscopic discharge) were protected and very much acknowledged by the patients. Longer term follow up might be required for patients to recognize any grievances repeat particularly in manual and substantial workers.

\section{References}

[1] R. Shiri, E. Viikari-Juntura, H. Varonen, M. Heliövaara, "Prevalence and determinants of lateral and medial epicondylitis: a population study," Am. J. Epidemiol; Vol.164(11), PP.1065-1074, 2006.

[2] F. W. Jobe , M. G. Ciccotti, "Lateral and medial epicondylitis of the elbow," JAAOS-Journal Am. Acad. Orthop. Surg; Vol.2(1), PP.1-8, 1994.

[3] S. Riek, A. E. Chapman, T. Milner, "A simulation of muscle force and internal kinematics of extensor carpi radialis brevis during backhand tennis stroke: implications for injury," Clin. Biomech; Vol.14(7), PP.477-483, 1999.

[4] B. C. Halpern, S. Chaudhury, S. A. Rodeo, "The role of platelet-rich plasma in inducing musculoskeletal tissue healing," HSS Journal@;Vol.8(2), PP.137-145, 2012.

[5] F. H. Savoie III, W. VanSice, M. J. O’Brien,
"Arthroscopic tennis elbow release," J. shoulder Elb. Surg; Vol.19(2), PP.31-36, 2010.

[6] G. Merolla , "Arthroscopic debridement versus platelet-rich plasma injection: a prospective, randomized, comparative study of chronic lateral epicondylitis with a nearly 2-year follow-up," Arthrosc. J. Arthrosc. Relat. Surg; Vol.33(7), PP.1320-1329, 2017.

[7] Z. Ahmad, "The effect of platelet-rich plasma on clinical outcomes in lateral epicondylitis," Arthrosc. J. Arthrosc. Relat. Surg; Vol.29(11), PP.1851-1862, 2013.

[8] A. Arirachakaran, A. Sukthuayat, T. Sisayanarane, S. Laoratanavoraphong, W. Kanchanatawan, J. Kongtharvonskul, "Platelet-rich plasma versus autologous blood versus steroid injection in lateral epicondylitis: systematic review and network metaanalysis," J. Orthop. Traumatol; Vol.17(2), PP.101112, 2016.

[9] T. P. Krogh , "Comparative effectiveness of injection therapies in lateral epicondylitis: a systematic review and network meta-analysis of randomized controlled trials," Am. J. Sports Med; Vol.41(6), PP.1435-1446, 2013.

[10] R. P. Nirschl , F. A. Pettrone, "Tennis elbow. The surgical treatment of lateral epicondylitis.," J. Bone Joint Surg. Am; Vol.61(6), PP.832-839, 1979.

[11] M. Y. Lo , M. R. Safran, "Surgical treatment of lateral epicondylitis: a systematic review," Clin. Orthop. Relat. Res; Vol.463, PP.98-106, 2007.

[12] J. H. Dunn, J. J. Kim, L. Davis, R. P. Nirschl, “Tento 14-year follow-up of the Nirschl surgical technique for lateral epicondylitis," Am. J. Sports Med; Vol.36 (2), PP.261-266, 2008. 